\title{
Lipoprotein redox status evaluation as a marker of cardiovascular disease risk in patients with inflammatory disease
}

\author{
ANCA UNGURIANU ${ }^{1}$, DENISA MARGINA $\breve{~}^{1}$, DANIELA GRĂDINARU ${ }^{1}$, CLAUDIA BĂCANU $^{1}$, \\ MIHAELA ILIE ${ }^{2}$, CHRISTINA TSITSIMPIKOU ${ }^{3}$, KONSTANTINOS TSAROUHAS $^{4}$, \\ DEMETRIOS A. SPANDIDOS ${ }^{5}$ and ARISTIDES M. TSATSAKIS ${ }^{6}$
}

\begin{abstract}
Departments of ${ }^{1}$ Biochemistry and ${ }^{2}$ Toxicology, Faculty of Pharmacy, Carol Davila University of Medicine and Pharmacy, Bucharest 020956, Romania; ${ }^{3}$ Department of Hazardous Substances, Mixtures and Articles, General Chemical State Laboratory of Greece, Athens $115121 ;{ }^{4}$ Cardiological Department, University Hospital of Larissa, Larissa 41110; ${ }^{5}$ Laboratory of Clinical Virology, School of Medicine, University of Crete; ${ }^{6}$ Department of Forensic Sciences and Toxicology, Faculty of Medicine, University of Crete, Heraklion 71003, Greece
\end{abstract}

Received August 29,2016; Accepted November 14, 2016

DOI: $10.3892 / \mathrm{mmr} .2016 .5972$

\begin{abstract}
Patients with chronic inflammatory disorders (ID) have an increased risk of developing cardiovascular disease, and routinely determined parameters do not reveal the real metabolic status of specific subgroups, such as patients with rheumatoid arthritis (RA). In this study, in order to evaluate state of the art markers for the assessment of cardiometabolic risk, abnormalities in lipoprotein levels in patients with a low-grade inflammatory status [diabetes mellitus (DM) subgroup] and in patients with a high systemic inflammatory burden (RA subgroup) was determined. The study group comprised patients with ID [DM $(n=20)$ and RA $(n=20)]$, with an aged-matched control group $(n=17)$. Patient serum was used to determine routine biochemical parameters and to isolate low-density lipoprotein (LDL) and high-density lipoprotein (HDL). The heparin-citrate method was used for LDL precipitation and the phosphotungstic acid- $\mathrm{MgCl}_{2}$ technique for the isolation of HDL. Further, Amplex Red and advanced oxidation protein product (AOPP) assays were applied to determine lipid peroxides and protein oxidation, respectively, while the levels of serum advanced glycation end products (AGEs) were also determined. Although the differences in the routinely determined lipidemic profile were notable between the DM and RA subgroups, markers of lipid
\end{abstract}

Correspondence to: Dr Denisa Margină, Department of Biochemistry, Faculty of Pharmacy, Carol Davila University of Medicine and Pharmacy, 6 Traian Vuia Street, Bucharest 020956, Romania

E-mail: denisa.margina@gmail.com

Key words: advanced oxidation protein products, advanced glycation end products, oxidized low-density lipoprotein, oxidized high-density lipoprotein, chronic inflammation peroxidation and of advanced protein oxidation/glycation did not differ significantly, indicating possible similar oxidative damage of serum lipoproteins. On the whole, as alterations in lipoprotein functionality can occur long before any changes in routinely measured biochemical parameters are observed, more sensitive markers for the assessment of cardiovascular risk are required. As AOPPs, AGEs, oxidized LDL (oxLDL) and especially oxidized HDL (oxHDL) are affected during the early stages of inflammatory disease, and due to their known link to coronary artery disease, it would be wise to include these markers in the routine cardiovascular evaluation of patients with chronic inflammatory disease, such as those with RA.

\section{Introduction}

Rheumatoid arthritis (RA) affects nearly $1 \%$ of the general population and is characterized by a high systemic inflammatory burden, with reduced life expectancy and increased mortality (1). Patients with RA present with a high prevalence of cardiovascular disease (CVD) and a high risk of developing fatal cardiac events, while traditional risk factors do not adequately reflect the increased probability of myocardial infarction, stroke or heart failure development (2-4).

In contrast to the high inflammatory status of patients with RA, a low-grade state of inflammation is currently associated with the progression of other metabolic disorders, such as atherosclerosis and diabetes mellitus (DM) (5).

The increased CV risk of RA patients is comparable to DM patients, although clinical profiles differ (6-8). Apart from traditional risk factors, the chronic inflammatory status of these patients is a prime contributor to their increased risk of developing CVD, promoting subtle changes in lipid levels, as well as in the levels of low-density lipoprotein (LDL), high-density lipoprotein (HDL) and triglycerides (TGs) $(1,6,8)$

Usually, a reduction in serum lipid levels is thought to have a positive impact on the prevention of CVD. However, this is not the case for patients with RA. Clinical studies have demonstrated an improvement in the patients' inflammatory 
status by applying biological and non-biological therapies, with a decrease in CVD risk along with an increase in lipid levels (6-9). Thus, when employing the classical approach of analyzing lipid profiles in patients with RA, their risk of developing CVD could be misestimated (6).

On the other hand, in patients with type $2 \mathrm{DM}$, characterized by subclinical, low-grade chronic inflammation (10), the development of atherosclerosis is promoted by tumor necrosis factor (TNF)- $\alpha$, interleukin (IL)- $1 \alpha$, IL-1 $\beta$, IL-4, fibrinogen or C-reactive protein (CRP) $(5,8)$. These pro-inflammatory molecules, apart from inducing endothelial and vessel abnormalities, have also been shown to induce changes in patient lipid profiles, alter insulin sensitivity and increase oxidative stress $(5,8)$. The systemic inflammatory burden, found in patients with RA and DM, is further linked to an accelerated atherosclerotic process, with increased plaque instability and a high risk of life-threatening cardiovascular events $(7,8)$.

Inflammation and oxidative stress-linked enzymes, such as myeloperoxidase, are capable of associating with both LDL and HDL, and can lead to profound alterations in their structure $(11,12)$. Although serum HDL levels characterizing patients with RA do not differ significantly from those of the normal population (13), it is thought that high-grade inflammation determines a significant decline in HDL functionality, along with important changes in their proteome, leading to a loss of their protective, anti-inflammatory and anti-atherogenic properties $(1,6,8,9,12,14)$. Oxidized HDL (oxHDL) is abundantly found in atherosclerotic plaques and is thought to be linked with an increased risk for the development of coronary artery disease (15). However, data on increased oxHDL levels in patients with RA are limited in medical literature $(1,2)$.

In patients with DM, the continuous state of hyperglycemia and low-grade inflammation accelerate lipoprotein oxidation through oxidative pathways involving the superoxide anion, leading to augmented LDL and HDL susceptibility to peroxidation $(1,11,12)$. The characteristic inflammatory state of these patients seems to have a deeper impact upon HDL levels, as these are highly sensitive to this process (16). Alterations in HDL lipidome (TG enrichment and decrease in cholesterol esters in the lipid core), as well as in its proteome [changes in apolipoprotein (Apo)-AI conformation and in the overall protein composition] (12), lead to dysfunctional particles and subsequently, to an increased risk of CVD, as among their many metabolic effects, the vasculo-protective ones are more easily affected (16).

The present study aimed to evaluate lipoprotein functionality in a group of patients with inflammatory disorders (ID), RA and DM, assessing both lipid peroxidation and advanced oxidative changes in their protein cargo. Our objective was to compare changes/abnormalities in lipoprotein levels in patients characterized by a low-grade inflammatory state (DM subgroup) as opposed to patients with a high-grade inflammatory burden (RA subgroup) for the better assessment of the risk of CVD in patients with chronic inflammatory diseases.

\section{Materials and methods}

Study design. The study population included 57 subjects (26 males and 31 females), with ages varying from 50 to 88 years, selected from patients admitted to the 'Ana Aslan'
National Institute of Gerontology and Geriatrics (NIGG) and 'Humanitas CD' Clinic (HCDC) in Bucharest, Romania. The subjects were enrolled in 2 groups: the ID group, which comprised 2 subgroups [patients with type 2 DM $(n=20)$ and patients with RA $(n=20)]$, and the aged matched control group $(n=17)$, with similar demographic characteristics with the study group.

The exclusion criteria included insulin treatment, prior history of myocardial infarction and stroke, anemia, renal impairment, infectious and neoplastic diseases. Patients using vitamin or any other antioxidant supplementation were also excluded.

The study protocol was approved by the 'Ana Aslan' NIGG and HDC Ethics Committees and all participants gave their written informed consent prior to entering the study. The study protocol conforms to the ethical guidelines of the 1975 Declaration of Helsinki.

Blood sampling. Venous blood samples were collected from all patients after an overnight 12 -h fasting period. Serum samples were centrifuged at $685 \mathrm{x} \mathrm{g}$, for $15 \mathrm{~min}$ at $4^{\circ} \mathrm{C}$ and stored at $-70^{\circ} \mathrm{C}$ until analysis.

Reagents. Heparin, purchased from Panpharma (LuitreFougeres, France) $(25,000 \mathrm{IU} / 5 \mathrm{ml})$ and sodium citrate from Merck Millipore (Billerica, MA, USA) were used to prepare an LDL precipitation solution of $100 \mathrm{IU}$ heparin $/ \mathrm{ml}$ in citrate buffer $0.064 \mathrm{M}$. The HDL assay solution was obtained from Merck Millipore (1.4 mmol/1 phosphotungstic acid, $8.6 \mathrm{mmol} / \mathrm{l}$ magnesium chloride). The Amplex Red probe from Life Technologies (Grand Island, NY, USA) was used to prepare a stock solution of $20 \mathrm{mM}$ in DMSO, from which a working solution of $300 \mu \mathrm{M}$ was prepared in $1 \mathrm{X}$ phosphate-buffered saline (PBS) (Biochrom AG, Berlin, Germany).

Biochemical and hematological parameters. Fasting glucose (GLY), total cholesterol (TC), LDL cholesterol, HDL cholesterol and TG levels were quantified by standard methods (Diagnostic Systems, Germany) on an Olympus AU400 Autoanalyzer.

LDL and HDL isolation. For the separation of LDL, we used a heparin $(100 \mathrm{IU} / \mathrm{ml})$-citrate buffer $(0.064 \mathrm{M})$, at a ratio of 1 to 9 (900 $\mu \mathrm{l}$ buffer for each $100 \mu \mathrm{l}$ of sample), followed by centrifugation at $685 \mathrm{x}$ g for $15 \mathrm{~min}$ and then LDL was suspended in 1X PBS (500 $\mu \mathrm{l}$ per sample).

For HDL separation, we used $1.4 \mathrm{mmol} / 1$ phosphotungstic acid, $8.6 \mathrm{mmol} / \mathrm{l}$ magnesium chloride solution to precipitate the LDL and very LDL (VLDL), the supernatant containing only the HDL. For each $200 \mu \mathrm{l}$ of serum, $500 \mu \mathrm{l}$ of precipitation solution were added and the mixture was centrifuged at $685 \mathrm{x}$ g for $15 \mathrm{~min}$. The HDL supernatant was separated from the VLDL/LDL precipitate and used for analysis.

Amplex Red assay. The method employed for determining lipid peroxidation was an Amplex Red based assay (17-19), a probe that can be used to determine lipid peroxides, as previously described by Tyurin et al (20). We used a previously described method (21) as follows: $50 \mu \mathrm{l}$ of the $300 \mu \mathrm{M}$ Amplex Red reagent were used for each $50 \mu \mathrm{l}$ of sample, incubated $30 \mathrm{~min}$ at 
room temperature, protected from light, followed by a dilution to $2 \mathrm{ml}$ with $1 \mathrm{X}$ PBS before the fluorimetric assay, which was performed on a Perkin Elmer Spectrofluorimeter (LS 50 B; Perkin Elmer, Rodgau, Germany), $\lambda_{\text {excitation }}=544 \mathrm{~nm}$ and $\lambda_{\text {emission }}=585 \mathrm{~nm}$.

Advanced oxidation protein product (AOPP) assay. AOPPs were determined spectrophotometrically (340 nm) using a commercially available assay kit (OxySelect STA-318; Cell Biolabs, Inc., San Diego, CA, USA); the concentration was expressed in chloramine $\mathrm{T}$ equivalents $(\mu \mathrm{mol} / \mathrm{l})$.

Advanced glycation end products (AGEs) assay. AGEs were determined as previously described by Kalousová et al (22) and Bartling et al (23). Firstly, the patient serum was diluted 1:25 with PBS, $\mathrm{pH} 7.4$, and the fluorescence intensity was then determined with a Perkin Elmer Spectrofluorimeter (LS 50 B; Perkin Elmer), $\lambda_{\text {excitation }}=350 \mathrm{~nm}$ and $\lambda_{\text {emission }}=440 \mathrm{~nm}$.

Statistical analysis. IBM SPSS (Armonk, NY, USA) statistical software was used for statistical analysis. The results are presented as the means \pm standard deviation for normally distributed values or median and interquartile range for not normally distributed ones. The Kolmogorov-Smirnov test was applied to assess normal distribution. For comparisons between groups, we used parametric tests (ANOVA and Student's t-test) and non-parametrical ones (Kruskal-Wallis and Mann-Whitney tests) for normally and not normally distributed data, respectively. To ascertain correlations between parameters, we applied the Spearman's Rank Correlation method; a value of $\mathrm{P}<0.05$ was considered to indicate a statistically significant difference. Simple or multiple linear regression analysis was performed (where possible considering linearity, normality and multi-co-linearity) in order to assess the influence of routinely determined parameters on markers of lipoprotein/protein oxidation.

\section{Results}

The demographic characteristics of the study group and subgroups are presented in Table I. The biochemical parameters of the ID group, the DM and RA subgroups and the control group are presented in Table II. The atherogenic index of plasma (AIP), a strong indicator of atherosclerosis, was calculated and equals to the decimal logarithm of the TG to HDL cholesterol ratio (24).

The HDL levels in the patients with RA did not differ significantly compared to those of the controls, but were significantly higher compared to those of the patients with $\mathrm{DM}(\mathrm{P}=0.005)$. On the other hand, HDL peroxidation was significantly higher in the patients with RA compared to the controls; however, no significant difference was observed compared to the patients with $\mathrm{DM}(\mathrm{P}=0.787)$.

Abnormal LDL levels were observed only in the patients with RA, taking into consideration that $80 \%$ of the patients with DM were receiving hypolipidemic treatment (considering as normal levels $<130 \mathrm{mg} / \mathrm{dl}$, according to the European Atherosclerosis Society guidelines), with disparity between groups $(\mathrm{P}=0.007)$. Regarding LDL peroxidation, no significant differences between oxidized LDL (oxLDL) in the DM and RA subgroups were observed.
Table I. Characteristics and administered medication in the different study groups.

\begin{tabular}{lccc}
\hline & ID & DM & $\begin{array}{c}\text { RA subgroup } \\
\text { (in remission } \\
\text { Parameters }\end{array}$ \\
\hline
\end{tabular}

General information

$\begin{array}{lccc}\text { Age, years } & 69.50 \pm 10.42 & 71.4 \pm 10.62 & 67.6 \pm 10.13 \\ \text { Males } & 19 & 11 & 8 \\ \text { Females } & 21 & 9 & 12\end{array}$

Co-morbidities

$\begin{array}{lrr}\text { AF } & 3 & 3 \\ \text { CAD } & 7 & 7 \\ \text { Obesity } & 7 & 7 \\ \text { Hypertension } & 14 & 14\end{array}$

Chronic treatment

$\begin{array}{lrr}\text { Furosemide } & 8 & 8 \\ \text { Spironolactone } & 5 & 8 \\ \text { ACE inhibitors } & 8 & \\ \text { Digoxin } & 2 & 3 \\ \text { Antiplatelets } & 7 & 6 \\ \text { Nitrates } & 3 & \\ \beta \text {-blockers } & 6 & \\ \text { ARB } & 4 & \\ \text { Calcium channel } & 7 & \\ \text { blockers } & & \\ \text { Antiarithmics } & 1 & \\ \text { Hypoglycemic } & 20 & \\ \text { medication } & & - \\ \text { Metformin and } & & \\ \text { sulfonylureas } & & \\ \text { Metformin } & & \\ \text { Statins } & 16 & \\ \text { NSAIDs } & 20 & \\ \text { DMARD } & & \end{array}$

8

5

8

2

ID, inflammatory disorders; DM, diabetes mellitus; RA, rheumatoid arthritis; AF, atrial fibrillation; ACE, angiotensin converting enzyme; $\mathrm{CAD}$, coronary heart disease; $\mathrm{ARB}$, angiotensin receptor blockers; DMARD, disease modifying antirheumatic drug, NSAIDs, non-steroidian anti-inflammatory drugs.

Of note, although the difference in glycemia between the 2 test groups was a highly significant one $(\mathrm{P}<0.001)$, this did not translate into significantly higher levels of AGEs, AOPP (AOPPs, AOPPldl or AOPPhdl) or lipoprotein peroxidation (oxLDL and oxHDL) (Table II). Even though hyperglycemia is the usual suspect in every metabolic derangement detected in DM, it seems that the low-grade inflammation contributes to profound alterations in lipoprotein structure and functionality, and consequently may be the culprit of vascular impairment.

It should be noted that no significant quantitative differences were observed between the patients with RA and the control group as regards the HDL, LDL, TC or TG levels ( $\mathrm{P}>0.05)$. 
Table II. Biochemical parameters monitored during the present study.

\begin{tabular}{lcccc}
\hline Biochemical parameter & Inflammatory group & Diabetes mellitus subgroup & Rheumatoid arthritis subgroup & Control group \\
\hline TC, mg/dl & $202 \pm 51.7$ & $179 \pm 43.8^{\mathrm{a}, \mathrm{c}}$ & $224 \pm 50.2$ & $179 \pm 19.9$ \\
$\mathrm{HDL}, \mathrm{mg} / \mathrm{dl}$ & $44.49(39.4-57.9)$ & $42.2 \pm 8.98^{\mathrm{a}, \mathrm{c}}$ & $57.6 \pm 17.3$ & $56.1 \pm 8.98$ \\
$\mathrm{LDL}, \mathrm{mg} / \mathrm{dl}$ & $120 \pm 42.8$ & $103 \pm 37.6^{\mathrm{a}, \mathrm{c}}$ & $142 \pm 39.9$ & $130(116-152)$ \\
$\mathrm{TG}, \mathrm{mg} / \mathrm{dl}$ & $110(84.9-170)$ & $111(102-222)$ & $108(68.0-144)$ & $121 \pm 45.9$ \\
$\mathrm{GLY}, \mathrm{mg} / \mathrm{dl}$ & $122(101-157)^{\mathrm{b}}$ & $166 \pm 57.3^{\mathrm{b}, \mathrm{c}}$ & $108 \pm 17.7$ & $104 \pm 11.4$ \\
oxLDL, RFU & $24.6(20.0-33.8)^{\mathrm{b}}$ & $22.5(19.0-34.2)^{\mathrm{b}}$ & $27.0 \pm 7.81^{\mathrm{b}}$ & $40.1(31.9-45.9)$ \\
oxHDL, RFU & $76.4(65.4-114)^{\mathrm{b}}$ & $74.1(64.4-124)^{\mathrm{b}}$ & $78.9(63.6-95.2)^{\mathrm{b}}$ & $55.4 \pm 14.9$ \\
$\mathrm{AGEs}, \mathrm{RFU}$ & $104 \pm 20.0^{\mathrm{b}}$ & $107 \pm 18.5^{\mathrm{b}}$ & $103 \pm 21.6^{\mathrm{b}}$ & $67.7 \pm 13.5$ \\
AOPPs, $\mu \mathrm{mol} / \mathrm{l}$ & $44.7 \pm 22.4^{\mathrm{b}}$ & $46.6 \pm 16.7^{\mathrm{b}}$ & $35.6(31.1,43.3)^{\mathrm{a}}$ & $31.4 \pm 9.99$ \\
AOPPldl, $\mu \mathrm{mol} / 1$ & $109 \pm 8.35^{\mathrm{b}}$ & $111(106-117)^{\mathrm{b}}$ & $108 \pm 5.92^{\mathrm{b}}$ & $94.9 \pm 10.6$ \\
AOPPhdl, $\mu \mathrm{mol} / \mathrm{l}$ & $71.3 \pm 31.0^{\mathrm{a}}$ & $62.8(46.0,98.2)$ & $70.8 \pm 31.6$ & $45.3(42.2,57.3)$ \\
AIP & $0.411 \pm 0.309$ & $0.540 \pm 0.255^{\mathrm{a}, \mathrm{c}}$ & $0.250 \pm 0.302$ & $0.325 \pm 0.264$
\end{tabular}

$\left.{ }^{\mathrm{a}} \mathrm{P}<0.05\right)$, ${ }^{\mathrm{b}} \mathrm{P}<0.01$, comparison with control group; ${ }^{\mathrm{C}} \mathrm{P}<0.01$, comparison with rheumatoid arthritis group. Values are reported as the means \pm standard deviation for normally distributed data and as median (percentile 25-percentile 75) for not normally distributed data. TC, total cholesterol; HDL, high-density lipoprotein; LDL, low-density lipoprotein; TG, triglyceride; GLY, glucose; oxLDL, oxidized LDL; oxHDL, oxidized HDL; AGEs, advanced glycation end products; AOPPs, advanced oxidation protein products; AIP, atherogenic index of plasma.

In order to determine the influence of the levels of TG, glycemia, TC and HDL, and AIP on the levels of AOPPs and AGEs in the ID group, multiple linear regression analysis was performed. The results are summarized below. The AGE levels were influenced by glycemia $\left(\mathrm{P}=0.014, \mathrm{R}^{2}=0.176\right)$, the TG levels $\left(\mathrm{P}=0.02, \mathrm{R}^{2}=0.205\right)$, TC levels $\left(\mathrm{P}=0.05, \mathrm{R}^{2}=0.212\right)$ and the levels of oxHDL $\left(\mathrm{P}=0.009, \mathrm{R}^{2}=0.187\right)$. It seems that TG levels have a greater impact on the variation of mean AGE levels compared to glycemia ( $\mathrm{P}=0.015$ vs. $\mathrm{P}=0.719$, with standardized co-efficients of 0.438 and 0.062 , respectively). AIP and glycemia were proven to be the main input variables for AOPPs $(\mathrm{P}<0.001)$. AGEs and AOPPs were also positively correlated $(\mathrm{r}=0.401, \mathrm{P}=0.01)$. Multivariate regression analysis was performed on possible factors affecting the levels of AOPPs in serum, presented as LgAOPPs $(-0.4112 \pm 0.14871)$. Regression analysis indicated that the AOPP levels were influenced by the glucose levels $\left(\mathrm{P}<0.001, \mathrm{R}^{2}=0.653\right)$, the TG levels $(\mathrm{P}<0.001$, $\left.\mathrm{R}^{2}=0.669\right)$ and the LDL levels $\left(\mathrm{P}=0.031, \mathrm{R}^{2}=0.202\right)$. The regression analysis revealed no significance of HDL and LDL in determining the LgAOPPs levels $(\mathrm{P}=0.071)$.

In the ID group, the Spearman's rank correlation method revealed significant correlations of AOPPs with HDL (negative correlation, $\mathrm{r}=-0.433 \mathrm{P}=0.011$ ) and oxHDL (positive correlation, $\mathrm{r}=0.403, \mathrm{P}=0.010)$. Furthermore, positive correlations were observed between GLY and AOPPs $(r=0.330, P=0.043)$ and oxHDL $(\mathrm{r}=0.495, \mathrm{P}=0.002)$, respectively.

As regards serum lipid levels, positive correlations were observed between the AOPP and TG levels $(\mathrm{r}=853, \mathrm{P}<0.001)$ and the TC levels $(\mathrm{r}=0.430, \mathrm{P}=0.006)$. In addition, an almost significant positive correlation $(\mathrm{r}=0.297, \mathrm{P}=0.067)$ was observed between the levels of TG and oxHDL, while a negative correlation with HDL serum levels was also noted $(\mathrm{r}=-0.552, \mathrm{P}=0.001)$.

The TG levels were linked to the levels of GLY ( $\mathrm{r}=0.418$, $\mathrm{P}=0.01)$ and AGEs in patient serum $(\mathrm{r}=0.342, \mathrm{P}=0.033)$.

Positive correlations between TC and TG with AOPPs were observed in both inflammatory subgroups,
Table III. Associations between lipids and markers of lipoprotein and protein peroxidation in the RA subgroup.

\begin{tabular}{lccc}
\hline Parameters & Correlation & r-value & P-value \\
\hline LDL & & & \\
TG & + & 0.561 & 0.03 \\
AOPPs & + & 0.639 & 0.01 \\
oxLDL & & & \\
AOPPldl & - & -0.457 & 0.043 \\
HDL & - & & \\
TG & - & -0.682 & 0.005 \\
AOPPs & - & -0.536 & 0.041 \\
oxHDL & - & & \\
AOPPhdl & - & -0.444 & 0.05 \\
\hline
\end{tabular}

RA, rheumatoid arthritis; LDL, low-density lipoprotein; HDL, high-density lipoprotein; TG, triglyceride; AOPPs, advanced oxidation protein products; oxLDL, oxidized LDL; oxHDL, oxidized HDL.

the DM subgroup $(\mathrm{P}=0.017$ and $\mathrm{P}<0.001)$ and the $\mathrm{RA}$ subgroup $(\mathrm{P}<0.001$ and $\mathrm{P}<0.001)$. Correlations were highly significant in the RA subgroup, although the serum levels were in the rather normal range. Thus, it is possible to argue that in patients with an increased systemic inflammatory burden, TG levels play a key role in the progression of oxidative damage of serum proteins.

Moreover, interesting correlations were found in the RA subgroup as regards the lipid profiles (Table III). While the correlations of LDL with TG and AOPPs were positive, the respective HDL correlations were negative. Furthermore, in both cases, negative correlations between the lipid peroxidation 
Table IV. Associations between AIP and lipids, markers of lipoprotein and protein peroxidation in the ID group and RA subgroup.

\begin{tabular}{lcccr}
\hline AIP & Parameters & Correlation & r-value & P-value \\
\hline ID & GLY & + & 0.403 & 0.022 \\
& AGEs & + & 0.356 & 0.039 \\
& AOPPs & + & 0.760 & $<0.001$ \\
\multirow{2}{*}{ RA } & AOPPs & + & 0.711 & 0.003 \\
& LDLox & + & 0.470 & 0.042 \\
& HDLox & + & 0.502 & 0.029 \\
\hline
\end{tabular}

AIP, atherogenic index of plasma; ID, inflammatory disorders; RA, rheumatoid arthritis; GLY, glucose; AGEs, advanced glycation end products; AOPPs, advanced oxidation protein products; oxLDL, oxidized low-density lipoprotein; oxHDL, oxidized high-density lipoprotein.

of lipoproteins (oxLDL and oxHDL) and AOPPs in the same lipoprotein fractions (AOPPldl, AOPPhdl) were reported.

The positive correlations of TG levels with AGEs ( $r=0.554$, $\mathrm{P}=0.014)$ and AOPPs $(\mathrm{r}=0.795, \mathrm{P}=0.000)$, along with the correlations of TC with AOPPs $(\mathrm{P}<0.001)$ indicate a strong correlation between lipid imbalances, advanced glycation and oxidative stress in patients with RA, although the serum levels of TG, TC and blood sugar were in the normal range and the patient lipid profiles can be reported as regular ones. This is in accordance with the previously reported correlation of high TG levels with pro-inflammatory and oxidative stress markers (25).

However, lipid peroxidation seems to be linked to an increase in blood glucose levels as positive correlations of glycemia with oxHDL were found in the ID group $(r=0.495$, $\mathrm{P}=0.002)$, in the DM subgroup $(\mathrm{r}=0.729, \mathrm{P}<0.001)$ and in the RA subgroup, although not a statistically significant one $(r=0.422, P=0.081)$. In order to determine the influence of glycemia on HDL peroxidation in patients with RA, presented as oxlgHDL (1.9154 \pm 0.1798$)$ to ensure a normal distribution, linear regression analysis was applied. Regression analysis revealed a significant influence $\left(\mathrm{P}=0.048, \mathrm{R}^{2}=0.173\right)$, while no such association was found for TG, LDL and TG, indicating that glycemia has the greatest influence on HDL peroxidation.

The correlations found in the ID group of TG with GLY, GLY with oxHDL, GLY and oxHDL with AOPPs were also significant in the DM subgroup $(r=0.589, P=0.006 ; r=0.729$, $\mathrm{P}<0.001 ; \mathrm{r}=0.475, \mathrm{P}=0.034$ and $\mathrm{r}=0.550, \mathrm{P}=0.012$, respectively).

As shown in Table IV, statistically bivariate correlations of AIP in the ID group and RA subgroup are presented. No significant correlations were observed in the DM group, probably as the lipid profile of diabetics was rather normal, under control with hypolipidemic drugs.

Moreover, the TG levels correlated significantly with the oxHDL levels $(r=0.496, P=0.026)$, and the oxLDL correlated with the AGE levels $(\mathrm{r}=0.546, \mathrm{P}=0.013)$ and AOPP levels $(r=0.469, P=0.037)$. High serum glucose levels, on the background of a continuous low-grade inflammatory state, promote both the lipid peroxidation of lipoproteins and oxidative alterations in serum proteins, leading to impaired structures that are unable to fulfill their physiological functions, becoming pro-inflammatory and pro-atherogenic.
It is important to establish a biochemical parameter that can indicate HDL dysfunction, leading to an increased risk of CVD. Although the levels of LDL, TC and TG were in the normal range in our DM subgroup, the peroxidation of HDL and LDL (oxHDL and oxLDL) was significantly higher compared to that of the controls $(\mathrm{P}<0.001$ and $\mathrm{P}=0.001$, respectively).

\section{Discussion}

The metabolic disarrangement caused by an ongoing state of oxidative stress and systemic inflammation leads to deep alterations in the proteome and lipidome of serum lipoproteins, lipids being the first to be altered, followed by a change in the protein cargo. Changes in LDL metabolism have been the longterm focus of CVD prevention and now dysfunctional HDL with a pro-inflammatory nature seems to play an important role the development of CVD (9). The current study, with the use of new markers, demonstrated that the levels of HDL and LDL oxidation were significantly increased in patients with RA compared to the controls, accompanied by a parallel increase in the oxidation of the protein component of respective particles.

In the case of subjects with a chronic inflammatory status, remission is of great importance as it has been shown that lipid profiles improve in patients with RA who underwent anti-inflammatory treatment and consequently entered remission $(8,9,26,27)$. A U-shaped curve of TC and LDL was observed in these subjects and also a non-linear correlation between LDL and cardiovascular risk, with an optimal serum LDL between 70-130 mg/dl (9). Moreover, the changes in HDL protein cargo are reversible, with a recovery of its protective anti-inflammatory functions $(9,16)$. Taking into consideration the implication of lipids, fatty acids in particular, in the inflammasome response, high cholesterol levels, but more importantly, high TG levels, can accelerate the increased oxidative burden of patients with chronic inflammatory disease.

The insignificant differences between the lipid profiles of patients with RA and the control subjects are in accordance with those of previous studies (13), and the small difference between diabetics and patients with RA as regards the peroxidation of serum lipoproteins (although the levels of lipoproteins differed significantly) could support the argument that the assessment of lipoprotein functionality is of great importance in determining alterations in their lipidome and may prevent the advancement of oxidative damage. It is interesting though that the LDL peroxidation levels in the controls were higher compared to the two test subgroups. Inflammation may be the culprit for this observation, as can determine an increase in the macrophage oxLDL uptake $(6,11,13)$. It is evident that when it comes to lipoprotein peroxidation, similarities appear between patients with DM and RA. In addition, they strengthen the argument that reducing LDL serum levels does not necessary entail a positive change in patient lipid profiles or in their risk of developing CVD. In patients with RA in particular, the 'lipid paradox' describes the inverse correlation of CVD risk with serum LDL and TC levels $(7,8)$. A notable decrease in the levels of TC and LDL, and in the TC/HDL ratio have been reported in the 5-year period before the clinical manifestations of RA appeared $(6,13)$. The mechanisms through which 
this occurs are not yet fully understood, but they seem to include reduced LDL synthesis, impaired cholesterol trafficking in the liver and the CRP-mediated uptake of LDL and oxLDL by macrophages $(6,8,13)$.

Moreover, an important association of oxidative stress with lipid imbalances and advanced glycation in RA was observed, although the serum levels of TG, TC and blood sugar were in the normal range and patient lipid profiles can be reported as regular in accordance with previously published data (25).

Cytokines seem to play a crucial part in the development of insulin resistance $(28,29)$; the hyperinsulinemia-hyperglycemia cycle and the continuous inflammatory burden lead to profound changes in the levels of lipoproteins and other serum proteins, leading to dysfunctional structures and atherosclerosis (30). Serum glucose, on the background of a continuous low-grade inflammatory state, along with lipid imbalances, promotes both the lipid peroxidation of lipoproteins and oxidative alterations in serum proteins, leading to impaired structures that are unable to fulfill their physiological functions, becoming pro-inflammatory and pro-atherogenic $(28,29,31)$.

AOPPs are a substantial marker for the assessment of oxidative damage in serum proteins, associated with the development of atherosclerosis and cardiovascular events (25). Our results support the hypothesis that under increased oxidative stress conditions accompanied by a chronically inflammatory burden, lipids are the first to be altered, followed by a change in lipoprotein proteome. In this context, hypertriglyceridemia plays a crucial role (32). Klafke et al found that hypertriglyceridemia was linked to oxidative stress, particularly AOPP levels, and pro-inflammatory markers in individuals with high TG and TC, but not in subjects with regular levels, and this association was independent of age, gender, body mass index, LDL, HDL and TC levels (25). In the current study, the said association was highly significant.

The assessment of HDL functionality should be advised, as only fully functional HDL can ensure protection against cardiovascular maladies. Our results indicate that TG and blood sugar levels are key factors in the advancement of oxidative changes in serum proteins and lipoproteins. More specific indicators of cardiometabolic risk are the markers of glycation and advanced oxidation of serum proteins, such as AOPPs and AGEs, and also the markers of lipid peroxidation, LDLox and HDLox.

In conclusion, patients with DM and RA undergo similar oxidative damage of serum lipoproteins. As regards the markers of advanced oxidation and glycation of serum proteins, they are only slightly higher in diabetics, with no significant difference between the two groups. These parameters have proven to be better indicators of the real metabolic status in the case of subjects with chronic inflammatory disease, as routinely determined ones are sometimes unable to reveal the functionality of some essential molecules.

\section{References}

1. Gómez Rosso L, Lhomme M, Meroño T, Sorroche P, Catoggio L, Soriano E, Saucedo C, Malah V, Dauteuille C, Boero L, et al: Altered lipidome and antioxidative activity of small, dense HDL in normolipidemic rheumatoid arthritis: Relevance of inflammation. Atherosclerosis 237: 652-660, 2014.
2. Vivekanandan-Giri A, Slocum JL, Byun J, Tang C, Sands RL, Gillespie BW, Heinecke JW, Saran R, Kaplan MJ and Pennathur S: High density lipoprotein is targeted for oxidation by myeloperoxidase in rheumatoid arthritis. Ann Rheum Dis 72: 1725-1731, 2013.

3. Boyer JF, Gourraud PA, Cantagrel A, Davignon JL and Constantin A: Traditional cardiovascular risk factors in rheumatoid arthritis: A meta-analysis. Joint Bone Spine 78: 179-183, 2011.

4. Negrei C, Bojinca V, Balanescu A, Bojinca M, Baconi D, Spandidos DA, Tsatsakis AM and Stan M: Management of rheumatoid arthritis: Impact and risks of various therapeutic approaches. Exp Ther Med 11: 1177-1183, 2016.

5. Akinkuolie AO, Pradhan AD, Buring JE, Ridker PM and Mora S: Novel protein glycan side-chain biomarker and risk of incident type 2 diabetes mellitus. Arterioscler Thromb Vasc Biol 35: 1544-1550, 2015.

6. Navarro-Millán I, Charles-Schoeman C, Yang S, Bathon JM, Bridges SL Jr, Chen L, Cofield SS, Dell'Italia LJ, Moreland LW, O'Dell JR, et al: Changes in lipoproteins associated with methotrexate or combination therapy in early rheumatoid arthritis: Results from the treatment of early rheumatoid arthritis trial. Arthritis Rheum 65: 1430-1438, 2013.

7. McGrath CM and Young SP: Lipid and Metabolic Changes in Rheumatoid Arthritis. Curr Rheumatol Rep 17: 57, 2015.

8. Choy E, Ganeshalingam K, Semb AG, Szekanecz Z and Nurmohamed M: Cardiovascular risk in rheumatoid arthritis: Recent advances in the understanding of the pivotal role of inflammation, risk predictors and the impact of treatment. Rheumatology (Oxford) 53: 2143-2154, 2014.

9. González-Gay MA and González-Juanatey C: Inflammation and lipid profile in rheumatoid arthritis: Bridging an apparent paradox. Ann Rheum Dis 73: 1281-1283, 2014.

10. Daniele G, Guardado Mendoza R, Winnier D, Fiorentino TV, Pengou Z, Cornell J, Andreozzi F, Jenkinson C, Cersosimo E, Federici $\mathrm{M}$, et al: The inflammatory status score including IL-6, TNF- $\alpha$, osteopontin, fractalkine, MCP-1 and adiponectin underlies whole-body insulin resistance and hyperglycemia in type 2 diabetes mellitus. Acta Diabetol 51: 123-131, 2014.

11. Yoshida $\mathrm{H}$ and Kisugi R: Mechanisms of LDL oxidation. Clin Chim Acta 411: 1875-1882, 2010

12. Rosenson RS, Brewer HB Jr, Ansell BJ, Barter P, Chapman MJ, Heinecke JW, Kontush A, Tall AR and Webb NR: Dysfunctional HDL and atherosclerotic cardiovascular disease. Nat Rev Cardiol 13: 48-60, 2016

13. Myasoedova E, Crowson CS, Kremers HM, Fitz-Gibbon PD, Therneau TM and Gabriel SE: Total cholesterol and LDL levels decrease before rheumatoid arthritis. Ann Rheum Dis 69: 1310-1314, 2010.

14. Li C, Tu Y, Liu TR, Guo ZG, Xie D, Zhong JK, Fan YZ and Lai WY: Rosiglitazone attenuates atherosclerosis and increases high-density lipoprotein function in atherosclerotic rabbits. Int J Mol Med 35: 715-723, 2015.

15. Huang Y, DiDonato JA, Levison BS, Schmitt D, Li L, Wu Y, Buffa J, Kim T, Gerstenecker GS, Gu X, et al: An abundant dysfunctional apolipoprotein A1 in human atheroma. Nat Med 20: 193-203, 2014.

16. O'Neill F, Riwanto M, Charakida M, Colin S, Manz J, McLoughlin E, Khan T, Klein N, Kay CW, Patel K, et al: Structural and functional changes in HDL with low grade and chronic inflammation. Int J Cardiol 188: 111-116, 2015.

17. Mishin V, Gray JP, Heck DE, Laskin DL and Laskin JD: Application of the Amplex red/horseradish peroxidase assay to measure hydrogen peroxide generation by recombinant microsomal enzymes. Free Radic Biol Med 48: 1485-1491, 2010.

18. Gomes A, Fernandes E and Lima JL: Fluorescence probes used for detection of reactive oxygen species. J Biochem Biophys Methods 65: 45-80, 2005.

19. Zhao B, Summers FA and Mason RP: Photooxidation of Amplex Red to resorufin: Implications of exposing the Amplex Red assay to light. Free Radic Biol Med 53: 1080-1087, 2012.

20. Tyurin VA, Tyurina YY, Ritov VB, Lysytsya A, Amoscato AA, Kochanek PM, Hamilton R, Dekosky ST, Greenberger JS, Bayir H, et al: Oxidative lipidomics of apoptosis: Quantitative assessment of phospholipid hydroperoxides in cells and tissues. Methods Mol Biol 610: 353-374, 2010.

21. Ungurianu A, Grădinaru D, Ilie M and Margină D: Fluorometric assays for measuring the redox status of HDL. In: Proceedings of INTERDIAB 2016: Diabetes mellitus as cardiovascular disease. ASRMN, Bucharest, pp477-489, 2016. 
22. Kalousová M, Skrha J and Zima T: Advanced glycation end-products and advanced oxidation protein products in patients with diabetes mellitus. Physiol Res 51: 597-604, 2002.

23. Bartling B, Hofmann HS, Sohst A, Hatzky Y, Somoza V, Silber RE and Simm A: Prognostic potential and tumor growth-inhibiting effect of plasma advanced glycation end products in non-small cell lung carcinoma. Mol Med 17: 980-989, 2011.

24. Chang Y, Li Y, Guo X, Dai D and Sun Y: The Association of Ideal Cardiovascular Health and Atherogenic Index of Plasma in Rural Population: A Cross-Sectional Study from Northeast China. Int J Environ Res Public Health 13: E1027, 2016.

25. Klafke JZ, Porto FG, Batista R, Bochi GV, Moresco RN, da Luz PL and Viecili PR: Association between hypertriglyceridemia and protein oxidation and proinflammatory markers in normocholesterolemic and hypercholesterolemic individuals. Clin Chim Acta 448: 50-57, 2015.

26. Kolahi S, Pourghassem Gargari B, Mesgari Abbasi M, Asghari Jafarabadi M and Ghamarzad Shishavan N: Effects of phylloquinone supplementation on lipid profile in women with rheumatoid arthritis: A double blind placebo controlled study. Nutr Res Pract 9: 186-191, 2015.

27. Govindan KP, Basha S, Ramesh V, Kumar CN and Swathi S: A comparative study on serum lipoprotein (a) and lipid profile between rheumatoid arthritis patients and normal subjects. J Pharm Bioallied Sci 7 (Suppl 1): S22-S25, 2015.
28. Dąbrowski P and Majdan M: Insulin resistance and metabolic syndrome - a different image of disorders in rheumatoid arthritis and ankylosing spondylitis. Wiad Lek 68: 235-241, 2015 (In Polish).

29. Costa NT, Veiga Iriyoda TM, Kallaur AP, Delongui F, Alfieri DF, Lozovoy MA, Amin RB, Delfino VD, Dichi I and Simão AN: Influence of Insulin Resistance and TNF- $\alpha$ on the Inflammatory Process, Oxidative Stress, and Disease Activity in Patients with Rheumatoid Arthritis. Oxid Med Cell Longev 2016: 8962763 , 2016.

30. Apostolakis S, Amanatidou V and Spandidos DA: Therapeutic implications of chemokine-mediated pathways in atherosclerosis: Realistic perspectives and utopias. Acta Pharmacol Sin 31: 1103-1110, 2010.

31. Liu J, Ren Y, Kang L and Zhang L: Oxidized low-density lipoprotein increases the proliferation and migration of human coronary artery smooth muscle cells through the upregulation of osteopontin. Int J Mol Med 33: 1341-1347, 2014.

32. Zafiropoulos A, Linardakis M, Jansen EH, Tsatsakis AM, Kafatos A and Tzanakakis GN: Paraoxonase $1 \mathrm{R} / \mathrm{Q}$ alleles are associated with differential accumulation of saturated versus 20:5n3 fatty acid in human adipose tissue. J Lipid Res 51: 1991-2000, 2010 